\title{
Effect of Ocimum sanctum against alloxan induced diabetes and biochemical alterations in rats
}

\author{
Shiv Kumar Jayant and Nalini Srivastava* \\ School of Studies in Biochemistry, Jiwaji University, Gwalior 474 011, India
}

\begin{abstract}
Diabetes is a group of metabolic disease and associated with impaired glucose metabolism, resulting from defect in insulin secretion, action and both. The present study was undertaken to evaluate the insulin secretion and anti-oxidative potential of Ocimum sanctum extract in diabetic rats. The results showed that extensive oxidative stress is generated in tissues of diabetic rats, increased the production of blood glucose, total cholesterol, triglyceride, creatinine, SGOT, SGPT, ALP and bilirubin, oxidative stress and decreased insulin secretion. Herbal medicines are widely used because of their effectiveness, no side effect and low cost. Treatment with aqueous suspension of Ocimum sanctum decrease serum glucose, total cholesterol, triglyceride, creatinine, SGOT, SGPT, ALP and bilirubin level in diabetic group as compared with control group. Aqueous suspension of Ocimum sanctum showed antidiabetic activity against diabetes.
\end{abstract}

\section{Introduction}

Diabetes mellitus is a chronic progressive metabolic disorder characterized by hyperglycemia mainly due to absolute or relative deficiency of insulin [1]. Diabetes mellitus virtually affects every system of the body mainly due to metabolic disturbances caused by hyperglycemia, especially if diabetes control over a period of time proves to be suboptimal. Diabetes associated with complications such as cardiovascular diseases, nephropathy, neuropathy and retinopathy which can lead to chronic morbidities and mortality [2,3]. World Health Organization (WHO) estimates that 350 million people worldwide have diabetic. This number is likely double by 2035 without any intervention. Almost $80 \%$ of diabetes deaths occur in low and middle income or developing countries [4]. According to WHO report, India today heads the world with over 33 million diabetic patients and this number is projected to increase to 80 million by the year 2035 [5].

In the last few years there has been an exponential growth in the field of herbal medicine and these drugs are gaining popularity both in developing and developed countries because of their natural origin and no side effects. Many traditional medicines in use and derived from medicinal plants, minerals and organic matter [6]. Number of medicinal plants, traditionally used for over 1000 years named rasayana is present in herbal preparations of Indian traditional health care systems [7]. In Indian systems of medicine most practitioners formulate and distribute their own recipes [8]. Medicinal plants are widely used in management of disease all over the world. The complications of diabetes are linked to oxidative stress induced by hyperglycemia which decreases natural antioxidant system. Diabetes is affect in lipid metabolism which is also the possibility of liver damage due to increase gluconeogenesis and ketogenesis.

Ocimum sanctum is one of the most popular herbs used in all of over world to reduce various risk factors associated with several diseases [9]. Aqueous suspension of Ocimum sanctum contains a variety of effective compounds that exhibit anticoagulant (anti-thrombotic) $[10,11]$, antioxidant [12,13], antibiotic [14], hypocholesterolaemic [15] and hypoglycaemic as well as hypotensive activities [16,17]. Aqueous suspension of Ocimum sanctum significantly decreases in the level of blood glucose, lipid profile and oxidative stress with a concomitant increase in glycogen and protein in diabetic rats [18]. This extracts also increased in insulin secreation and regeneration of $\beta$ islets cells. The present study was aim to investigate that the potential of aqueous suspension of Ocimum sanctum against alloxan induced diabetic rats, compared to normal control and diabetic control rats.

\section{Materials and methods}

Plant material: The fresh leaves of Ocimum sanctum (Tulsi) were collected from botanical garden in school of studies in Botany, jiwaji University, Gwalior. Aqueous suspension of Ocimum sanctum was prepared each day freshly.

Experimental animal: Male albino rats of Wistar strain (weight 120 $\pm 20 \mathrm{~g}$ ) was used in the proposed study. Animals were obtained from the animal facilities of Defence Research and Development Establishment, Gwalior, India, and were maintained under controlled conditions of temperature $\left(25^{\circ} \pm 2^{\circ} \mathrm{C}\right)$, relative humidity of $(50 \pm 15 \%)$, and normal photoperiod (light-dark cycle of $12 \mathrm{hrs}$ ) in the animal room of our department on standard pellet diet and tap water ad libitum. Animals were housed throughout the experiment in polypropylene cages (with each cage housing six animals) containing paddy husk as bedding and allowed to acclimatize to the environment of animal room for 7 days before the start of experiment. Animals were handled, ethically treated as per the rules and instructions of Ethical Committee of Animal Care (Ref No. IAEC/JU/2012/01) of Jiwaji University, Gwalior, India, in accordance with the Indian National law on animal care and use.

Correspondence to: Nalini Srivastava, School of Studies in Biochemistry, Jiwaji University, Gwalior 474 011, India, Tel: 09977710704; E-mail: patiya7aug@gmail.com

Key words: Alloxan, oxidative stress, Ocimum sanctum, hyperglycemia

Received: November 12, 2016; Accepted: December 19, 2016; Published: December 22, 2016 
Experimental design: Twenty four rats were randomly divided into four groups each group contain six rats and were given following treatments:

\section{Group 1 : Control (normal blood glucose level).}

Group 2: Treated control group (treated with aqueous suspension of Ocimum sanctum $2.5 \mathrm{mg} / \mathrm{kg}$ body weight).

Group 3 : Diabetic (I.V. injection of alloxan $70 \mathrm{mg} / \mathrm{kg}$ body weight).

Group 4: Treated diabetic group (treated with aqueous suspension of Ocimum sanctum $2.5 \mathrm{mg} / \mathrm{kg}$ body weight).

Induction of experimental diabetes and treatment with aqueous suspension of Ocimum sanctum: Type I diabetes was induced by giving single intravenous injection of alloxan monohydrate $70 \mathrm{mg} / \mathrm{kg}$ body weight, dissolved in $0.9 \%$ solution of sodium chloride [19]. The animals were checked for blood glucose level $48 \mathrm{~h}$ after alloxan injection, and blood sugar level above $200 \mathrm{mg} / \mathrm{dl}$ was used for the experiment.

Ocimum sanctum leaves were obtained from botanical garden, cleaned and aqueous suspension of Ocimum sanctum freshly prepared each day and $2.5 \mathrm{mg} / \mathrm{kg}$ body weight was given orally to the rats of group 2 and 4 with the help of cannula, daily for 14 days.

Blood sample collection: Blood was collected at after 14 days from eye orbital of rats with the help of capillary glass tube and centrifuged $1000 \mathrm{rpm}$ for $10 \mathrm{~min}$. at $4^{\circ} \mathrm{C}$ and serum sample collected. Serum sample all groups were analysed for various biochemical parameters at same time after 14 days of feeding rats.

Biochemical parameters: Fasting blood glucose levels were estimated by glucose oxidase peroxidase reactive strips [20] (AccuChek, Roche Diagnostics, USA). The biochemical parameters evaluated were serum lipid profiles [21,22] (Triglyceride and Total cholesterol), liver biomarkers such as, bilirubin [23], serum glutamate pyruvate transaminase (SGPT), serum glutamate oxaloacetate transaminase (SGOT) [24] and alkaline phosphatase (ALP) [25] using diagnostics kits.

Estimation of total cholesterol, triglyceride and creatinine: The lipid profile parameters such as total cholesterol (Cholesterol oxidaseperoxidase method) and serum triglyceride (GPO-POD Method) were calculated from Freidewald's Formula all the estimation were carried out fasting serum samples using commercial kits manufactured by Crest Biosystems India Pvt. Ltd.

The kidney function test such as serum creatinine (Mod. Jaffe's Kinetic method) were estimated by using kits manufactured by Crest Biosystems, India, Pvt. Ltd.

Estimation of SGPT, SGOT, bilirubin and ALP: SGPT also called as Alanine Aminotransferase (ALAT). It is found in a variety of tissues but is mainly found in liver. Increased levels are found in hepatitis, cirrhosis, obstructive jaundice and other hepatic diseases. Slight elevation of the enzyme is also seen in myocardial infarction. SGOT is an enzyme found mainly in heart muscle, liver cells, skeletal muscle and kidneys. Injury to these tissues results in the release of the enzyme in blood. Elevated levels are found in myocardial infarction, cardiac operations, Hepatitis, cirrhosis, acute pancreatitis, acute renal diseases, and primary muscle diseases. Decreased levels may be found in pregnancy, Beri-beri and Diabetic Ketoacidosis. The liver function test such as SGPT, SGOT (Modified IFCC method), bilirubin and ALP were estimated by using kits manufactured by Crest Biosystems, India, Pvt. Ltd.
Statistical analysis: Results are expressed as mean \pm S.E. of four different sets of observation taken on different days. All the statistical analyses were performed using one-way analysis of variance (ANOVA) with post hoc Dunnett's multiple comparison test applied across treatment groups for each tissue. Significance level was based on $p<0.05$.

\section{Result and discussion}

Alloxan administration to experimental rats selectively causes pancreatic $\beta$ cell disruption and cytotoxicity after its intracellular accumulation [26]. The anti hyperglycemic activity caused by tulsi extract is due to the presence of flavonoids and sulphur containing compounds. it is clearly observed that the serum lipid profile liver function test and glucose level was increased after the injection of alloxan in diabetic rats but after consistently treating with aqueous extract of tulsi for 14 days with normal diet, the shooting rate of serum cholesterol was increase in untreated diabetic rats where as it was decrease in treated diabetic rats. It is also reported that antioxidant property of the garlic which decrease the oxidative stress and resulting in lipid oxidation inhibition [27].

Lipid peroxidation is one of the characteristic features of chronic diabetes and insulin secretion is also closely associated with lipoxygenase derived peroxides [28]. Glutathione (GSH) is known to protect the cellular system against toxic effects of lipid peroxidation. The level of GSH decrease in the liver and kidney during diabetes represents its increase utilization due to oxidative stress [29].

The blood glucose level of all the rats was tested by taking the blood from the tail vein and using electronic glucometer. The antidiabetic effects of the extracts on the fasting blood sugar levels of diabetes (Table 1) and administration of alloxan (70 mg/kg, i.v) led to 3 fold elevation of fasting blood glucose levels, which was maintained for period of 14 days. It was observed that oral administration of Ocimum sanctum extracts significantly decreased the blood glucose levels in diabetic rats. The present study results showed that oral administration of Ocimum sanctum extracts daily for 14 days, to the diabetic rats caused $32.7 \%$ decrease on $7^{\text {th }}$ day and $56 \%$ decrease in the blood glucose level on 14 days of the start of treatmet (Table 1). The results clearly showed the hypoglycemic potential of Ocimum sanctum extracts.

The levels of SGOT, SGPT, ALP and bilirubin were significantly increased in alloxan induced diabetic rats. These adverse changes were reversed to near normal values in extracts of Ocimum sanctum treated. In the present study indicates the increase in the levels of SGOT, SGPT, ALP and bilirubin in serum when compared with control rat serum. The levels of SGOT, SGPT, ALP and bilirubin were increase $146 \%$, $213 \%, 500 \%, 190.1 \%$ increase in alloxan induced diabetic rat serum as compared with control rats (Table 2). Oral administration of Ocimum sanctum extracts for 14 days showed antidiabetic potential against alloxan diabetes induced alterations in the level of SGOT, SGPT, ALP and bilirubin. The levels of SGOT, SGPT, ALP and bilirubin were decreased by $38.6 \%, 42 \%, 78 \%, 46 \%$ in diabetic rats given Ocimum sanctum extracts treatment for 14 days when compared with diabetic control rats (Table 2).

The results showed total Cholesterol, triglyceride and creatinine levels were increased in alloxan induced diabetic rats. Total cholesterol, triglyceride and creatinine levels were increase $78.5 \%$ and $136.3 \%$ and $186 \%$ in alloxan induced diabetic rats when compared with control rats (Table 3). Diabetic rats treated with oral administration of Ocimum sanctum extracts for 14 days, caused $35.3 \%, 44.4 \%$ and $51 \%$ decrease 
Table 1. Effect of oral treatment of Ocimum sanctum extracts on glucose concentration in alloxan induced diabetic rats.

\begin{tabular}{|l|l|c|c|}
\hline S No. & Groups & $\mathbf{0 ~ d a y s}$ & $\mathbf{7}$ \\
\hline 1. & Control & $99.33 \pm 0.88$ & $103 \pm 1.15 \#$ \\
\hline 2. & Control + Ocimum sanctum & $94 \pm 1.73 \#$ & $92 \pm 1.15^{* *}$ \\
\hline 3. & Diabetic & $370.67 \pm 1.76^{* * *}$ & $378.67 \pm 0.88^{* * *}$ \\
\hline 4. & Diabetic + Ocimum sanctum & $365.67 \pm 1.76^{* * *}$ & $39.33 \pm 0.88^{* * *}$ \\
\hline
\end{tabular}

Few drop of blood was taken from the tail vein and glucose level was measured using electronic glucose meter. Blood glucose levels are expressed as mg/ dl; Results are mean \pm S.E. of four set of observation. ${ }^{*} \mathrm{P}<0.05,{ }^{*} \mathrm{P}<0.001, * * * \mathrm{P}<0.0001$ and ${ }^{*} \mathrm{P}>0.05$ when compared with respective control, comparison between diabetic and diabetic + treatment group; Control and diabetic rats were given aqueous suspension of Ocimum sanctumextracts orally, $2.5 \mathrm{mg} / \mathrm{kg}$ body weight with the help of cannula daily for 14 days.

Table 2. Effect of Ocimum sanctum extracts for 14 days in experimental rats on the levels of SGOT, SGPT, bilirubin and ALP in normal and diabetic rats.

\begin{tabular}{|l|l|c|c|c|}
\hline S No. & Groups & SGOT & SGPT & BLP \\
\hline 1. & Control & $52.54 \pm 0.75$ & $27.26 \pm 0.55$ & $0.28 \pm 0.01$ \\
\hline 2. & Control + Ocimum sanctum & $48.06 \pm 0.77 *$ & $24.43 \pm 0.6 *$ & $0.23 \pm 0.01^{*}$ \\
\hline 3. & Diabetic & $129.33 \pm 0.63 * * *$ & $85.44 \pm 0.63 * * *$ & $1.68 \pm 0.04 * * *$ \\
\hline 4. & Diabetic + Ocimum sanctum & $79.45 \pm 0.69 * * *$ & $49.4 \pm 0.56$ & $213.38 \pm 0.7 * * *$ \\
\hline
\end{tabular}

SGOT and SGPT is expressed as U/L. Bilirubin and ALP concentration is expressed as $\mathrm{mg} / \mathrm{dl}$. Results are mean $\pm \mathrm{S}$.E. of four set of observation. $* \mathrm{P}<0.05, * * \mathrm{P}<0.001, * * * \mathrm{P}<0.0001$ and ${ }^{\#} \mathrm{P}>0.05$ when compared with respective control, comparison between diabetic and diabetic + treatment group; Control and diabetic rats were given aqueous suspension of Ocimum sanctumextracts orally, $2.5 \mathrm{mg} / \mathrm{kg}$ body weight with the help of cannula daily for 14 days.

Table 3. Effect of Ocimum sanctum extracts for 14 days in experimental rats on the levels of Total Cholesterol, Triglyceride and Creatinine in normal and diabetic rats.

\begin{tabular}{|l|l|c|c|}
\hline S No. & Groups & Total cholesterol & Triglyceride \\
\hline 1. & Control & $147 \pm 1.73$ & $82.67 \pm 1.76$ \\
\hline 2. & Control + Ocimum sanctum & $140.67 \pm 1.2 *$ & $75 \pm 1.73 *$ \\
\hline 3. & Diabetic & $262.33 \pm 2.91 * * *$ & $0.5 \pm 0.01$ \\
\hline 4. & Diabetic + Ocimum sanctum & $169.67 \pm 1.2 * * *$ & $195.33 \pm 2.33 * * *$ \\
\hline
\end{tabular}

Total cholesterol, Triglyceride and creatinine concentration is expressed as $\mathrm{mg} / \mathrm{dl}$. Results are mean $\pm \mathrm{S}$.E. of four set of observation. $* \mathrm{P}<0.05, * * \mathrm{P}<0.001, * * * \mathrm{P}<0.0001$ and ${ }^{\#} \mathrm{P}>0.05$ when compared with respective control, comparison between diabetic and diabetic + treatment group; Control and diabetic rats were given aqueous suspension of Ocimum sanctum extracts orally, $2.5 \mathrm{mg} / \mathrm{kg}$ body weight with the help of cannula daily for 14 days.

total cholesterol, triglyceride and creatinine levels as compared with diabetic rats. Control rats treated with oral administration of Ocimum sanctum extracts decrease $4.3 \%, 9.3 \%$ and $28 \%$ level of total cholesterol, triglyceride and creatinine when compared with control rats.

\section{Conclusion}

Our data clearly indicate that in diabetic increased oxidative stress which causes peroxidative membrane damage. Diabetes inhibited the activities of antioxidant enzymes and insulin secretion by pancreatic beta cells. Oral administration of Ocimum sanctum extracts increase insulin activity and reduced oxidative stress complication in diabetic rats. Further human studies are necessary and found the active component of Ocimum sanctum and role of these herbal drugs in controlling diabetes and its complications.

\section{Acknowledgments}

These study data have not been presented any previously studies and conference. SKJ perform the experiments, collected the data, developed the figures, analysed the data and wrote the article. NS conceptualized the study, analysed and discussed the data of the article.

\section{Conflict of interest}

The authors declare no conflict of interest.

\section{Funding}

Mr. SKJ has received stipend from the Department of Higher Education, Government of M.P., Bhopal, India. The financial support from the Department of Science and Technology, N. Delhi, India, in the form of FIST grant to the school is thankfully acknowledged.

\section{References}

1. Zargar AH, Wani AA, Laway BA, Masoodi SR, Wani AI, et al. (2008) Prevalence of diabetes mellitus and other abnormalities of glucose tolerance in young adults aged 20-40 years in North India (Kashmir Valley). Diabetes Res ClinPract 82: 276-281. [crossref]

2. American Diabetes Association (2004) Implications of the United Kingdom Prospective Diabetes Study. Diabetes Care 27: S28-32.[crossref]

3. Zucchi P, Ferrari P, Spina ML (2005) [Diabetic foot: from diagnosis to therapy]. $G$ ItalNefrol 22 Suppl 31: S20-22. [crossref]

4. World health organization. Diabetes Factsheet 2012.[crossref]

5. Mohan D, Raj D, Shanthirani CS, Datta M, Unwin NC, et al. (2005) Awareness and knowledge of diabetes in Chennai - The Chennai urban rural epidemiology study. $J$ Assoc Physicians India 53: 283-287.

6. Grover JK, Yadav S, Vats V (2002) Medicinal plants of India with anti-diabetic potential. J Ethnopharmacol 81: 81-100. [crossref]

7. Scartezzini P, Speroni E (2000) Review on some plants of Indian traditional medicine with antioxidant activity. $J$ Ethnopharmacol 71: 23-43. [crossref]

8. Seth SD, Sharma B (2004) Medicinal plants in India. Indian J Med Res 120: 9-11 [crossref]

9. Hussein HEMA, Jamil K, Rao M (2001) Hypoglycemic, hypolipidemic and antioxidant properties of tulsi (Ocimum sanctum Linn) on streptozotocin induced diabetes in rats. IndJ clinBiochem 16:190-194.[crossref]

10. Augusti KT, Sheela CG (1996) Antiperoxide effect of S-allyl cysteine sulfoxide, an insulin secretagogue, in diabetic rats. Experientia 52: 115-120. [crossref]

11. Anwar MM, Meki AR (2003) Oxidative stress in streptozotocin-induced diabetic rats: effects of garlic oil and melatonin. Comp BiochemPhysiol A MolIntegrPhysiol 135 539-547. [crossref]

12. Bakri IM, Douglas CW (2005) Inhibitory effect of garlic extract on oral bacteria. Arch Oral Biol 50: 645-651. [crossref]

13. Gupta B, Kumar VN, Mallaiah S (2013) Assessment of Antimicrobial Activity of Various Concentrations of Commercially Available Tulsi (Ocimum Sanctum) Powder 
against Streptococcus Mutans. Open J Dentistry and Oral Medic 1: 19-24.[crossref]

14. Kiesewetter H, Jung F, Pindur G, Jung EM, Mrowietz C, et al. (1991) Effect of garlic on thrombocyte aggregation, microcirculation, and other risk factors. Int Clin Pharmacol Ther Toxicol 29: 151-155. [crossref]

15. Ali M, Thomson M (1995) Consumption of a garlic clove a day could be beneficial in preventing thrombosis. Prostaglandins Leukot Essent Fatty Acids 53: 211-222.

16. Ali M, Al-Qattan KK, Al-Enezi F, Khanafer RM, Mustafa T (2000) Effect of allicin from garlic powder on serum lipids and blood pressure in rats fed with a high cholesterol diet. Prostaglandins LeukotEssent Fatty Acids 62:253-259. [crossref]

17. Banerjee SK, Maulik SK (2002) Effect of garlic on cardiovascular disorders: a review. Nutr J 1: 4. [crossref]

18. Narendhirakannan RT, Subramanian S, Kandaswamy M (2006) Mineral content of some medicinal plants used in the treatment of diabetes mellitus. Biol trace elements Res 103:109-115.[crossref]

19. Resmi CR, Venukumar MR, Latha MS (2006) Antioxidant activity of Albizzialebbeck (Linn.) Benth. inalloxan diabetic rats. Indian J Physiol Pharmacol 50: 297-302. [crossref]

20. Trinder P (1969) Determination of glucose in blood using glucose oxidase with an alternative oxygen acceptor. Ann Clin Biochem 6: 24-27.[crossref]
21. Van Handel E, Zilversmit DB (1957) Micromethod for the direct determination of serum triglycerides. $J$ Lab Clin Med 50: 152-157.[crossref]

22. Allain CC, Poon LS, Chan CS, Richmond W, Fu PC (1974) Enzymatic determination of total serum cholesterol. Clin Chem 20: 470-475. [crossref]

23. Malloy HT, Evelyn KA (1937) The determination of bilirubin with the photometric colorimeter. J Biol Chem 119: 481-490.[crossref]

24. King J (1965) The transaminases: alanine and aspartate transaminases. 15. In: Van D, editor. Practical clinical enzymology. Van D Nostrand Co 363-395.

25. King J (1965) The hydrolases-acid and alkaline phosphatases. In: 16. Van D, editor Practical clinical enzymology. Van D Nostrand Co 199-208.

26. Mathew PT, Augusti KT (1973) Studies on the effect of allicin (diallyldisulphide-oxide) on alloxan diabetes I. Hypoglycaemic action and enhancement of serum insulin effect and glycogen synthesis. Indian J Biochem Biophys 10: 209-212.[crossref]

27. Anuradha CV, Selvam R (1993) Effect of oral methionine on tissue lipid and antioxidant in alloxan induced diabetic rats. $J$ Nutr Biochem 4: 212-217.

28. Felig P, Marliss E, Ohman JL, Cahill CF Jr (1970) Plasma amino acid levels in diabetic ketoacidosis. Diabetes 19: 727-728.[crossref]

29. Metz SA (1984) Is phospholipase A2 a "glucose sensor" responsible for the phasic pattern of insulin release? Prostaglandins 27: 147-158.[crossref]

Copyright: $(02016$ Jayant SK. This is an open-access article distributed under the terms of the Creative Commons Attribution License, which permits unrestricted use, distribution, and reproduction in any medium, provided the original author and source are credited. 